\title{
Axial Compression Behaviors of the Steel Tube Confined Reinforced Concrete Columns with Binding Bars
}

\author{
Hao Hu $\mathbb{D}^{1,2}{\text { Zhengliang } \mathrm{Li}^{3}{ }^{3} \mathrm{Xi} \mathrm{Tu}^{3}{ }^{3} \text { and Junfeng Tang }}^{3}$ \\ ${ }^{1}$ School of Civil Engineering, Chongqing University of Arts and Sciences, Chongqing 402160, China \\ ${ }^{2}$ Institute of Civil Engineering Disaster Prevention and Reduction, Chongqing University of Arts and Sciences, \\ Chongqing 402160, China \\ ${ }^{3}$ School of Civil Engineering, Chongqing University, Chongqing 400045, China \\ Correspondence should be addressed to Hao Hu; hhxkfy@126.com
}

Received 12 November 2020; Revised 30 November 2020; Accepted 16 December 2020; Published 28 December 2020

Academic Editor: Peng Zhang

Copyright (c) $2020 \mathrm{Hao} \mathrm{Hu}$ et al. This is an open access article distributed under the Creative Commons Attribution License, which permits unrestricted use, distribution, and reproduction in any medium, provided the original work is properly cited.

\begin{abstract}
An experimental study on the steel tube confined reinforced concrete (STCRC) column with binding bars under axial compression is conducted. The bearing capacity and failure modes are obtained. It can be known that the axial deformation of concrete occurred under compression. The core concrete is wrapped and constrained by the steel tube wall, and the steel tube wall is constrained by binding bars locally, so the local buckling shape of the wall between the binding bars is like wave shape. The 3D finite element model is also developed to analyze the behavior of this type of column under axial compression. Good agreement is shown between the test and predicted results in terms of the load-deformation curves and ultimate strength. The parametric studies indicate that the spacing of binding bars, diameter of longitudinal bars, concrete strength, thickness of the steel tube wall, and section dimension of the column generate different influence on the mechanical properties and bearing capacity. The diameter of longitudinal bars, concrete strength, and section dimension of the column have a great effect on the ultimate bearing capacity. The numerical results also show that the spacing of binding bars has little effect on the ultimate bearing capacity. The larger thickness of the steel tube wall leads to adverse effect on the specimen performance. Finally, the theoretical calculation is carried out, and the result is good.
\end{abstract}

\section{Introduction}

Due to the shortcomings of concrete-filled steel tubular (CFST) columns which have poor binding effect on core concrete leading to low bearing capacity and poor ductility, some improved methods on CFST columns have been investigated by scholars.

Ge and Usami [1] reported the experimental results of square CFST columns with and without longitudinal stiffeners under concentric compressive load studied on the strength and deformation of specimens. Huang et al. [2, 3] presented the axial load behavior of CFST columns of square section stiffened with steel reinforcing ties forming an octagonal shape; however, the construction is difficult, and the quality is not easy to guarantee for the columns. Ding et al. $[4,5]$ discussed the mechanical performances of round- ended CFST columns which may be used as bridge piers under axial loading by experimental study and finite element analysis. The influences of width-thickness ratio, concrete strength, steel yield strength, and wall thickness of the steel tube on the ultimate bearing capacity of the CFST columns were studied. Xia et al. [6] investigated the improving mechanism of reinforcement on load transformer performance of CFST columns with high-strength concrete and thin-walled steel tube (where the thickness is $1.2 \mathrm{~mm}$ ) subjected to axial compression and concluded that reinforcement was more effective to improve the performance than enlarging the wall thickness of steel tubes.

In order to further improve the confined effect of the steel tube on concrete, CFST with binding bars and steel tube confined reinforced concrete (STCRC) columns have been put forward by some scholars. 
Cai and $\mathrm{He}[7,8]$ proposed a constitutive relationship for square CFST columns with binding bars, and a calculation of complete load-stress relationship curves was conducted for some certain experimental specimens using this constitutive relationship. Experimental investigation and theoretical research on specially shaped (L-, T-, and cross-shaped) CFST columns with binding bars were shown by Long et al. [9-12]. Finite element analyses of rectangular CFST columns with binding bars were carried out using five material models including von Mises, Mohr-Coulomb, Drucker-Prager, smeared cracking, and damaged plasticity by Chen and Zhou [13]. Ren et al. [14] reported that the axial compression mechanism of round-ended CFST short columns with binding bars was carried out with different diameters of the binding bar, concrete strength, distance between binding bars, steel content of section, height-width ratio, etc.

STCRC is a kind of composite member that is similar to CFST by wrapping the thin-walled steel tube on the outside of concrete and confining it. However, steel tube wall does not directly bear external load, which is disconnected at the joint for the connection conveniently between the reinforced concrete column and beam. Zhang et al. [15] discussed axial compression test and analysis of circular section STCRC columns with high-strength concrete. Zhou et al. [16, 17] investigated the mechanical performances of square STCRC short columns by test and then reported the axial load behavior of circular section STCRC columns with different length-to-diameter ratios. Gao et al. [18] completed properties of 12 STCRC columns with different steel tube diameterthickness ratios, slender ratio, and loading eccentricity ratio by test, and effective experience was obtained.

Based on the above research, it is easy to know that steel tubes and binding bars all provide constraint effects on concrete. However, studies on the collective effect from them on concrete are rare. Considering the advantages of STCRC and binding bars, a new type of component named STCRC column with binding bars is proposed in this paper. When the STCRC column with binding bars is loaded under axial compression, the core concrete is pressed first because both ends of the outer steel tube are shorter than those of the core concrete. The steel tube and binding bars are not directly loaded, which mainly confine the concrete. So, the test study, the finite element analysis, and theoretical calculation on this kind of component are carried out under axial compression in order to provide the reference for the engineering design.

\section{Experimental Program}

2.1. Specimen and Material. In order to investigate the mechanical properties of the square-tubed reinforced concrete column with binding bars, an axial compression specimen is made. The average concrete properties are all from material quality testing: $f_{\mathrm{cu}}, f_{c}, \varepsilon_{o}$, and $\varepsilon_{c}$ are cube compressive strength, uniaxial compressive strength, yield strain, and ultimate strain, respectively, where $f_{\mathrm{cu}}=43.7 \mathrm{MPa}, f_{c}=33.2 \mathrm{MPa}, \varepsilon_{o}=0.002$, and $\varepsilon_{c}=0.0033$. The steel reinforcement bars are of $400 \mathrm{MPa}$ grade with the diameters of longitudinal and binding bars $14 \mathrm{~mm}$ and $6 \mathrm{~mm}$, respectively, where $\mathrm{HRB} 400, \mathrm{C} 14$, and C6. The grade
Q235 thin-walled steel tube has a thickness of $2 \mathrm{~mm}$. The mechanical properties of steel from material quality testing are shown in Table 1 , where $E$ is the elastic modulus, $f_{y}$ is the yield strength, and $f_{u}$ is the ultimate strength.

The specimen is adopted in the test as shown in Figure 1. Before assembling the member, circular holes on the steel walls were made by punching where the binding bars are arranged. Each binding bar joins together with the steel tube through two circular stiffening steel plates on its two ends by welding, which is detailed in Figure 1(b).

\subsection{Experimental Setup and Instrumentation. The specimen} is tested by an electric-hydraulic serving compression machine with a capacity of $20,000 \mathrm{kN}$. The compressive load is applied from the top of the specimen through a force loading mode. The load pattern is uniaxial monotonic loading. After the load-displacement curve becomes nonlinear, load is increased slowly and continuously until final failure and data are recorded continuously.

The axial deformation of the concrete column and strains of longitudinal bars, binding bars, and steel tube are measured in this test. The axial deformation is obtained by the electric-hydraulic serving compression machine. Strain gauges are placed on the tube wall to measure vertical strain and hoop strain of the steel tube wall. Strain gauges are placed on longitudinal bars and some binding bars to measure the tension strains of the bars. Experimental setup and instrumentation are shown in Figure 2.

\section{Test Results and Analysis}

3.1. Failure Mode. The failure modes of the specimen on each tube face are shown in Figure 3. The axial deformation of concrete occurred under compression, by which transverse expansion deformation of concrete is caused. The core concrete is wrapped and constrained by the steel tube wall, and the steel tube wall is constrained by binding bars locally, so local buckling of the wall between the binding bars is like wave shape.

3.2. Load-Strain and Load-Displacement Responses. As shown in Figure 4, the variation on strain of longitudinal reinforcements with the axial load $P$ can be seen, where the negative sign represents compressive strain. From Figures $4(\mathrm{a}) \sim 4(\mathrm{c})$, the strains of the angular reinforcements $\mathrm{ZA}$ and $\mathrm{ZB}$ are greater than the ones of $\mathrm{ZC}$ and $\mathrm{ZD}$. From Figures $4(\mathrm{~d}) \sim 4(\mathrm{f})$, the strains of the reinforcements $\mathrm{ZE}, \mathrm{ZF}$, $\mathrm{ZG}$, and $\mathrm{ZH}$ are greater than the ones of $\mathrm{ZI}, \mathrm{ZJ}, \mathrm{ZK}$, and ZL. This is because that it is difficult to ensure the uniform symmetry of concrete and steel bars in the concrete casting procedure, by which the specimen under the axial pressure lightly becomes the one under eccentric compression. Stress on both faces $\mathrm{A}$ and $\mathrm{B}$ of the specimen is greater than that on both faces $\mathrm{C}$ and $\mathrm{D}$ by which the compression deformation of the angular reinforcement $\mathrm{ZB}$ and concrete near it is induced bigger, as shown in Figure 5. It can also be seen that the microstrains at the measuring points are close to $2000 \mu \varepsilon$, 
TABLE 1: Mechanical properties of steel from material quality testing.

\begin{tabular}{lccc}
\hline Steel reinforcement and tube & $E(\mathrm{MPa})$ & $f_{y}(\mathrm{MPa})$ & $f_{u}(\mathrm{MPa})$ \\
\hline C6 & 217897.33 & 482.00 & 644.33 \\
C14 & 206675.67 & 482.00 & 580.33 \\
Q235 & 161702.67 & 158.00 & 265.67 \\
\hline
\end{tabular}

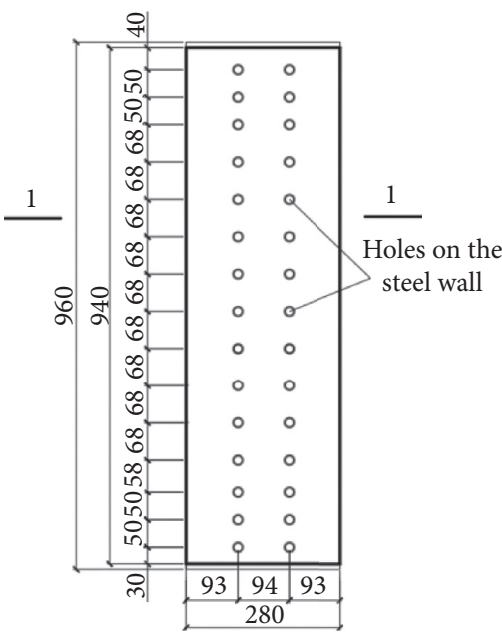

(a)

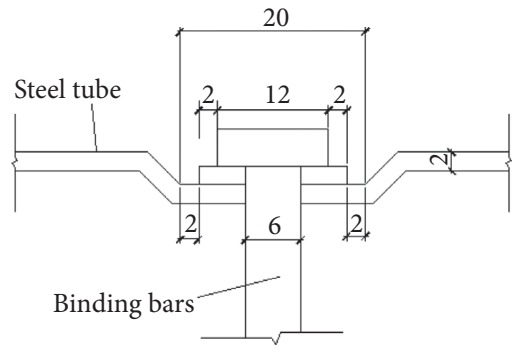

(b)

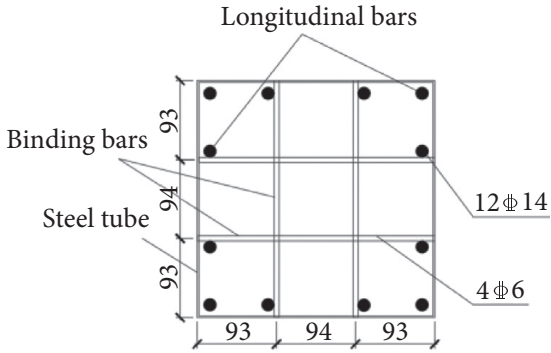

1-1

Figure 1: Dimension and detailing of specimens (unit: $\mathrm{mm}$ ): (a) elevation drawing, (b) detail of binding bar construction, and (c) section of reinforcing bars.

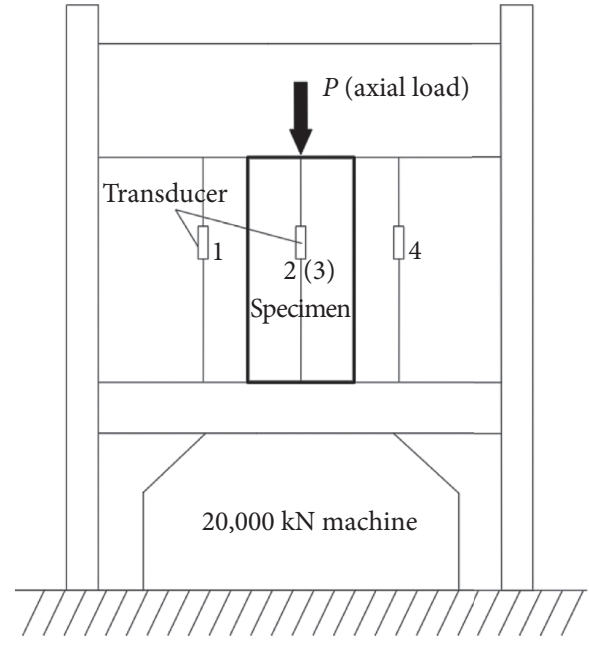

(a)

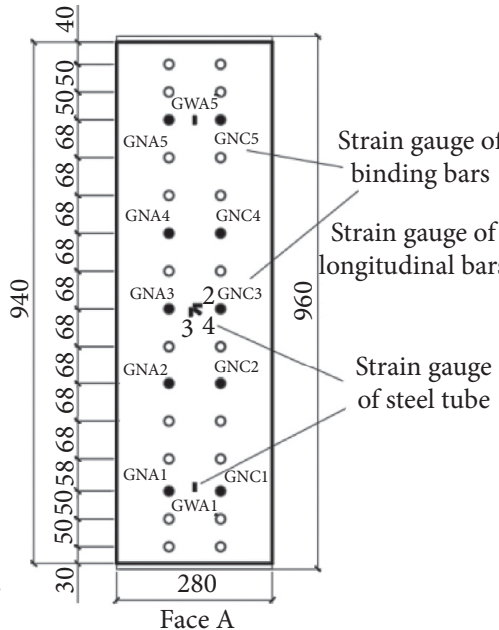

(b)

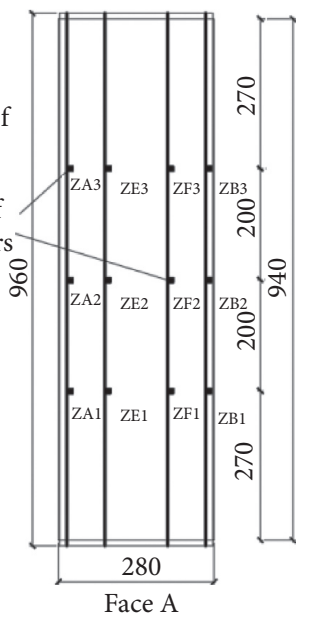

(c)

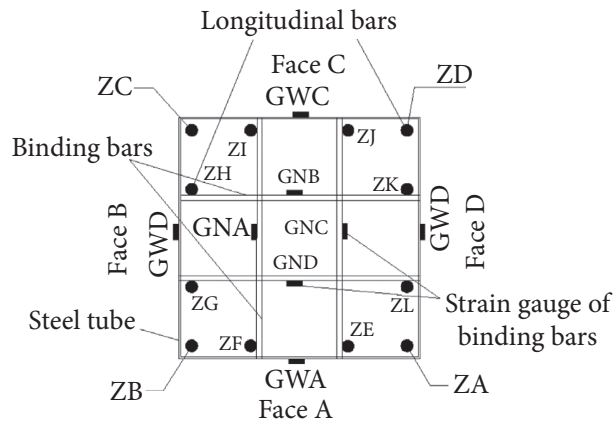

(d)

FIGURE 2: Sketch of test setup and location of strain gauges: (a) test setup, (b) binding bars and steel tube, (c) longitudinal bars, and (d) plane arrangement chart. 


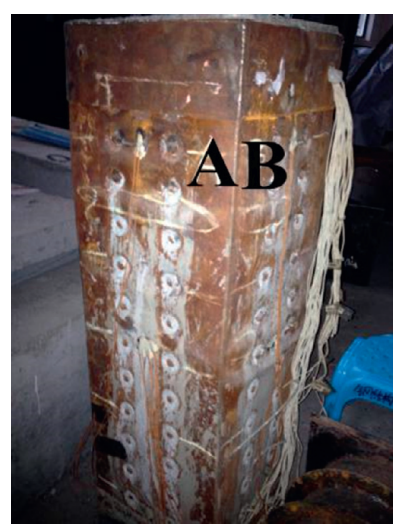

(a)

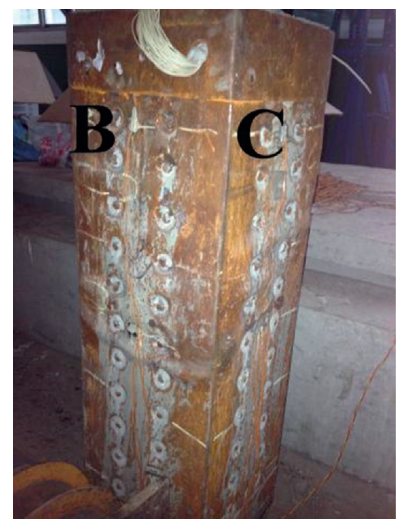

(b)

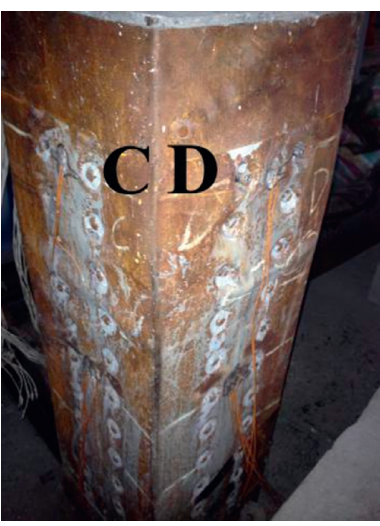

(c)

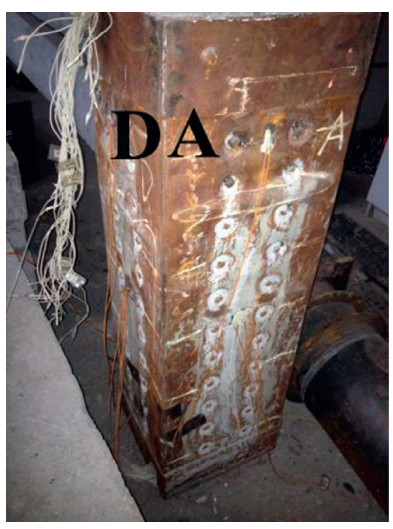

(d)

Figure 3: Failure modes.
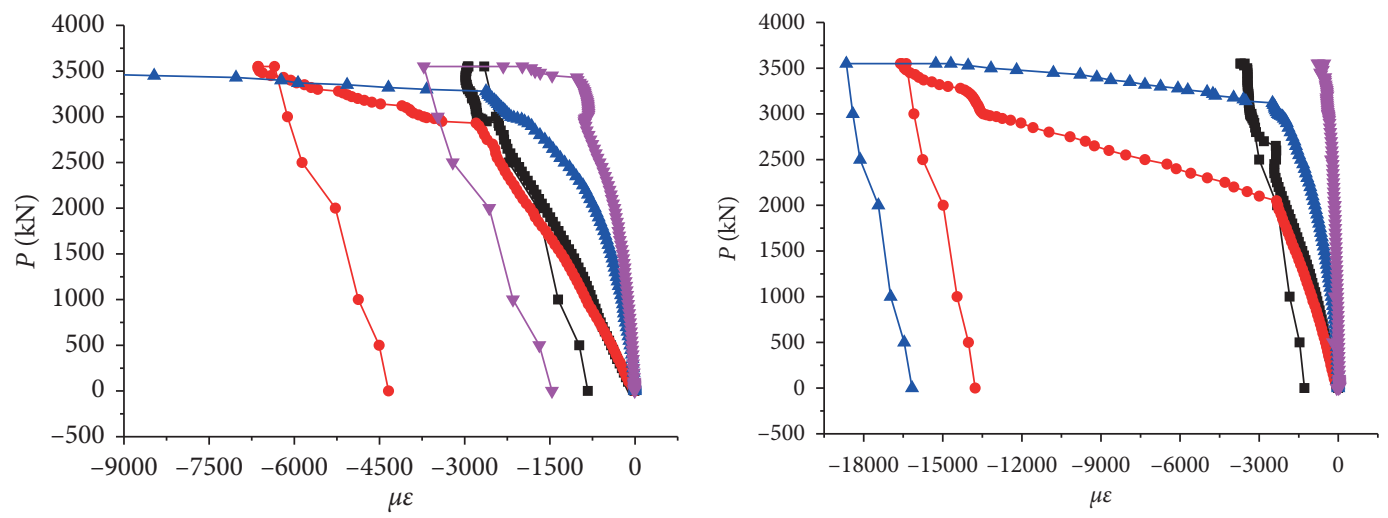

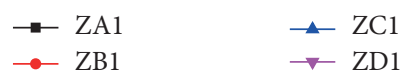

(a)

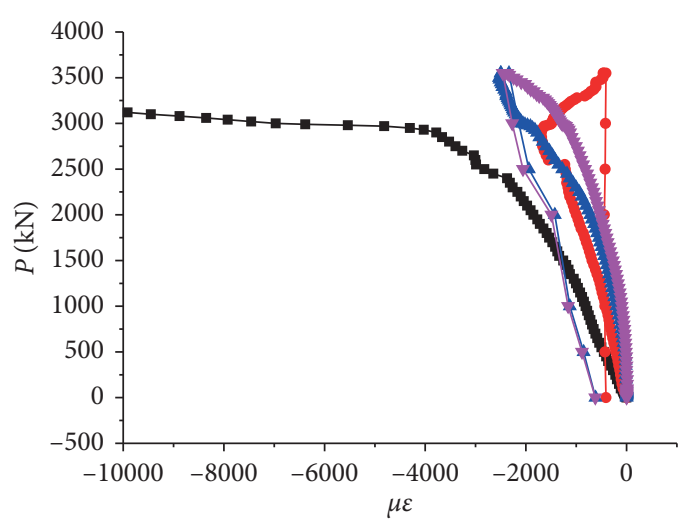

$\rightarrow-\mathrm{ZA} 2$

$\simeq \mathrm{ZC} 2$

(b)

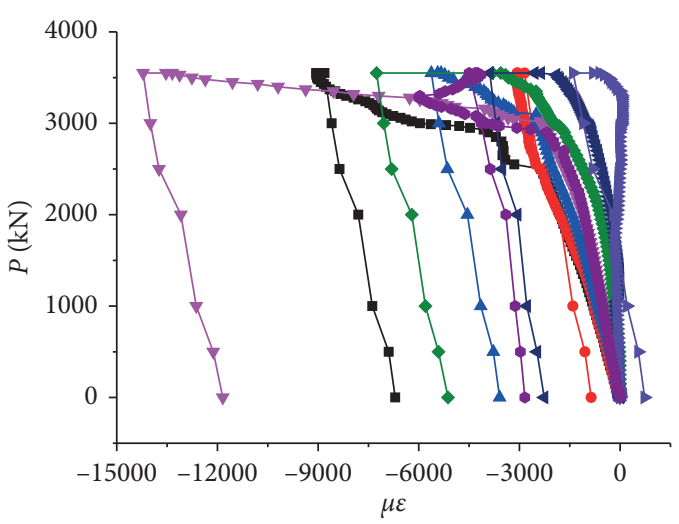

(c)

$$
\begin{array}{lll}
-\mathrm{ZE} 1 & \rightarrow \mathrm{ZH} 1 & \rightarrow \mathrm{ZK} 1 \\
-\mathrm{ZF} 1 & \rightarrow \mathrm{ZI} 1 \quad \rightarrow \mathrm{ZL} 1
\end{array}
$$

(d)

Figure 4: Continued. 


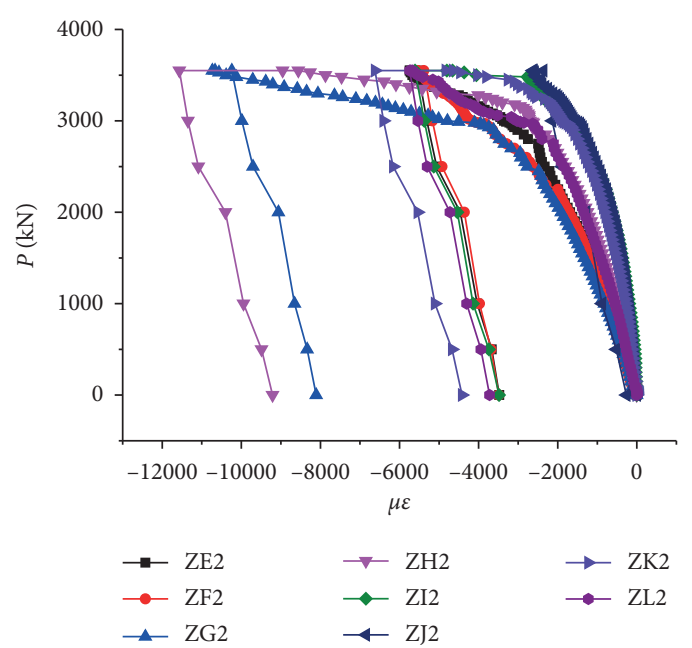

(e)

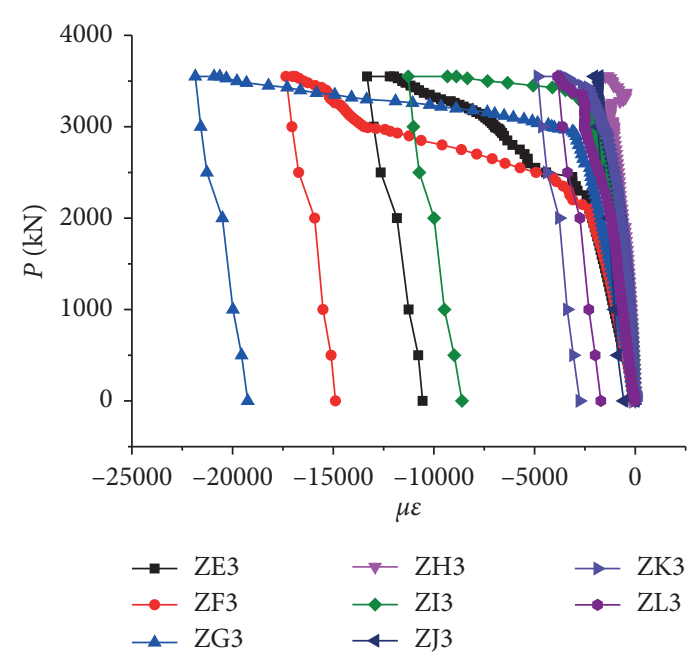

(f)

Figure 4: Load-strain curves of longitudinal bars.

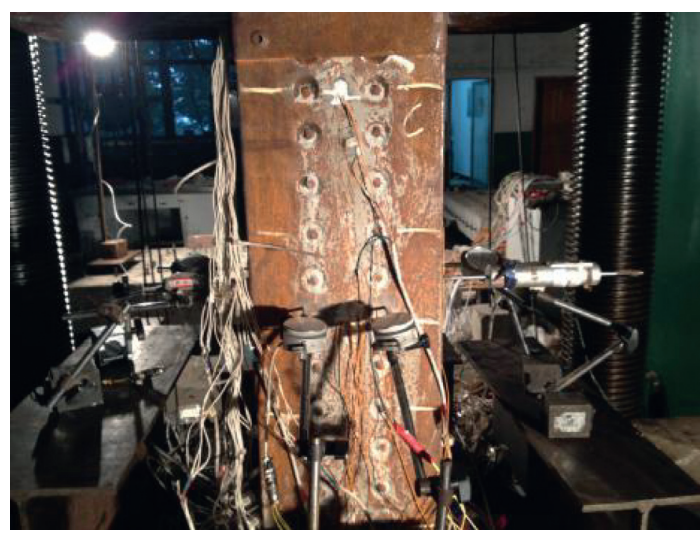

Figure 5: The specimen is inclined to the $\mathrm{B}$ face.

and the steel bars basically begin to yield when the load is applied near $2200 \mathrm{kN}$.

As shown in Figure 6, the variation curves of tensile strain with axial pressure of binding bars at different height sections of the column are given. The tension strains at the measuring points GNB and GND are larger than those at the points GNA and GNC from Figures 6(a) and 6(b). The tensile strains of the binding bars are close to each other in Figures 6(c) and 6(d), and it can be known that the bending deformation of the column body in this section is very small. Figure 6(e) shows that the tensile strains at all measuring points are larger than those of Figures $6(\mathrm{a}) \sim 6(\mathrm{~d})$, which indicates that the upper deformation of the column is more obvious. It can also be seen from Figure 6 that the upper binding bars of the column begin to yield when the axial pressure is applied to near $1600 \mathrm{kN}$; while the load is applied to $3000 \mathrm{kN}$, the tension bars yield completely.

As shown in Figure 7, the variation curves of the strain with the axial pressure of the steel tube at different positions are given. The strains on face $\mathrm{A}$ of the steel tube wall are very large. The strains on face $\mathrm{A}$ at both ends of the column are much larger than those of the other three faces especially, and the strains on the other three faces at both ends are very close to each other. In Figure 7(b), the strains at the measuring points of the wall are basically in the elastic range and are very small mainly due to the transverse strains measured here. However, the axial strains of the steel wall basically reach the yield value.

The curve between axial load $P$ and average axial displacement $\Delta$ is shown in Figure 8. It can be seen that the load is applied to the maximum value $P_{\max }=3490 \mathrm{kN}$ corresponding to the displacement $\Delta_{\max }=5.9 \mathrm{~mm}$.

\section{Finite Element Analysis}

4.1. Model Description. In order to study the axial compression members of STCRC with binding bars and to verify the effectiveness of the finite element model at the same time, numerical simulation analysis for the test specimen is conducted by using finite element software ANSYS.

The stress-strain curve of the steel tube is simulated by the bilinear isotropic hardening (BISO) model in ANSYS program, meeting von Mises yield criterion, and the plastic modulus of the hardening section is 0.01 times of the initial elastic modulus. The $\mathrm{W}-\mathrm{W}$ failure criterion is defined by the order "TB, concr, matnum" for the concrete material model. The stress-strain relationship of concrete before cracking and crushing is linear. After cracking and crushing, the multilinear kinematic hardening (KINH) model is adopted for the constitutive relation of concrete.

The concrete is simulated by using SOLID65 element. The steel tube, end plates, and stiffening plates are simulated by using SOLID187 element. Initial defects of the component and the mutual slippage between concrete and steel tube were ignored. The longitudinal reinforcements and binding bars are simulated by using LINK180 element. In order to facilitate mesh generation, the circular holes on the steel walls are replaced by square ones. The lower surface of 

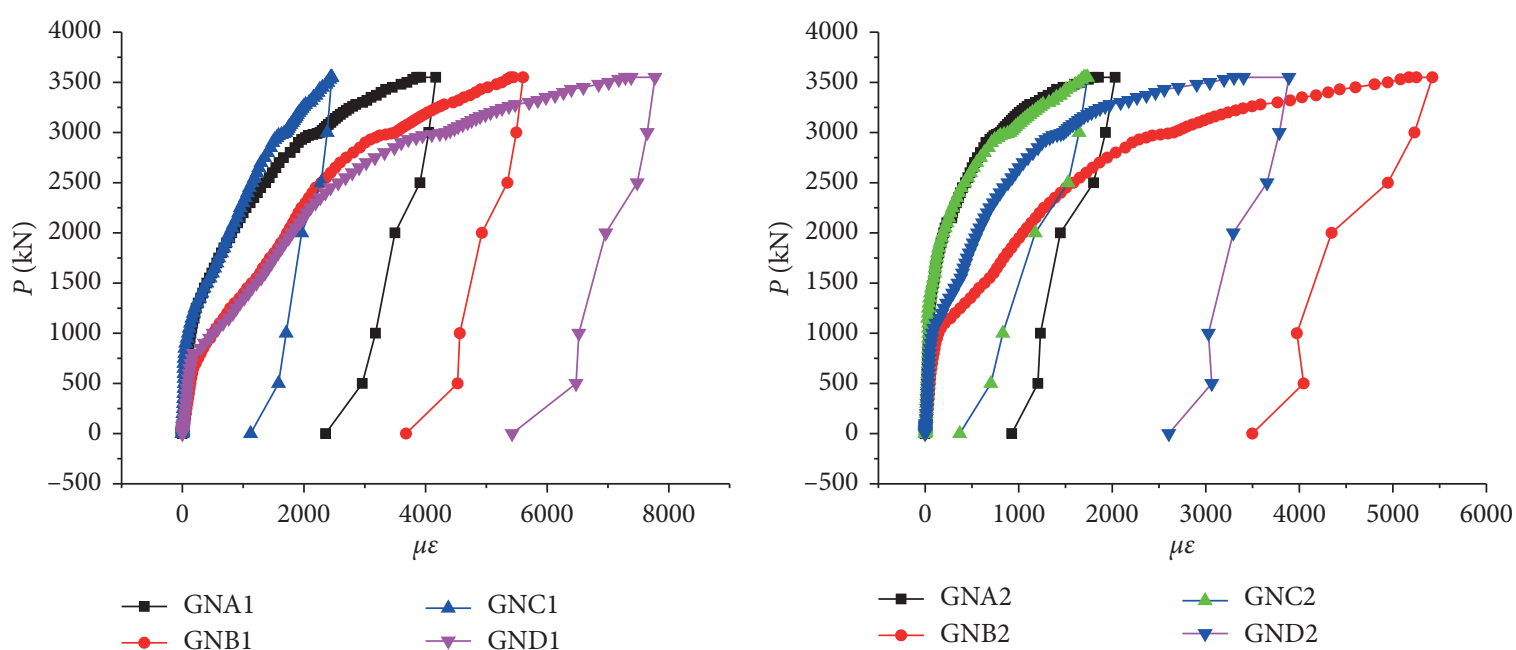

(a)
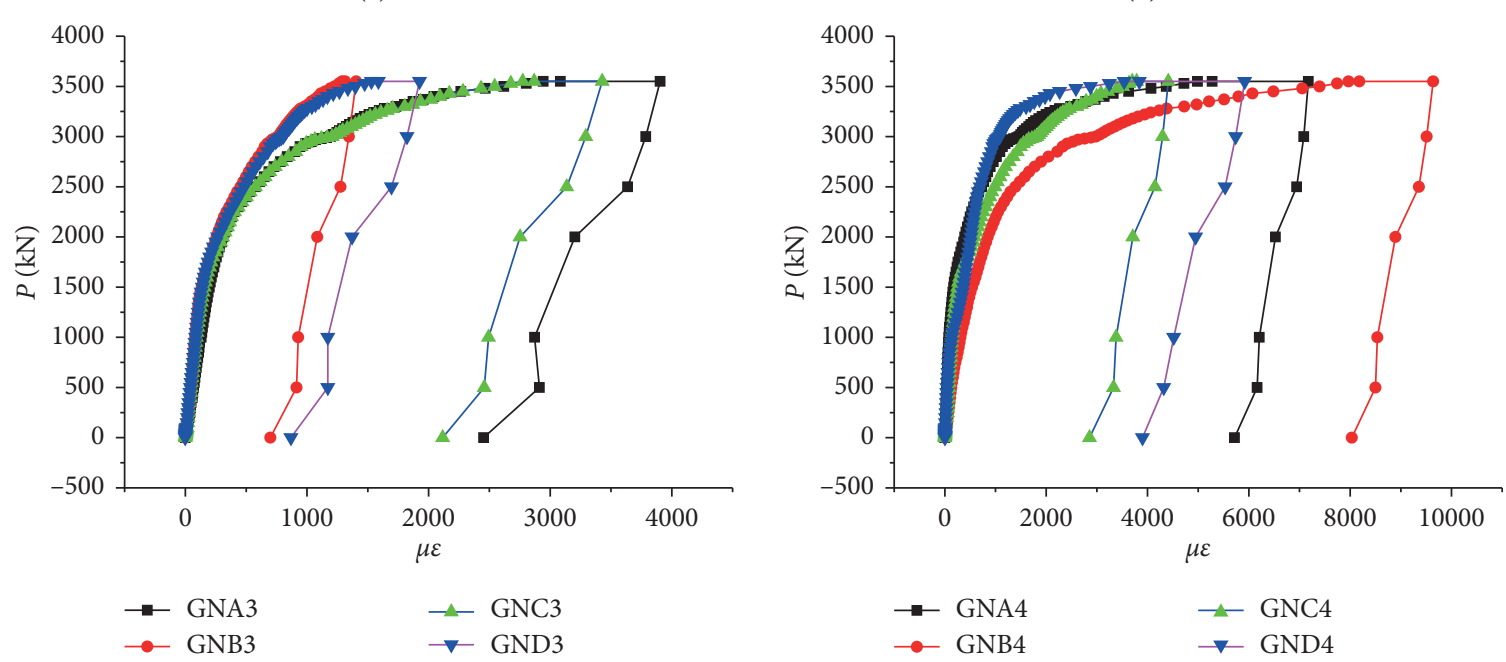

(c)

(d)

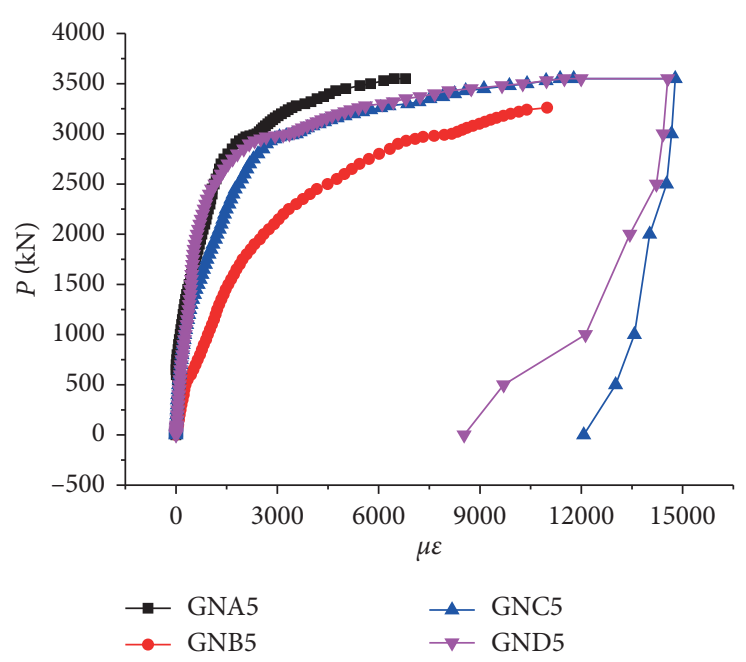

(e)

FIGURE 6: Load-strain curves of binding bars. 


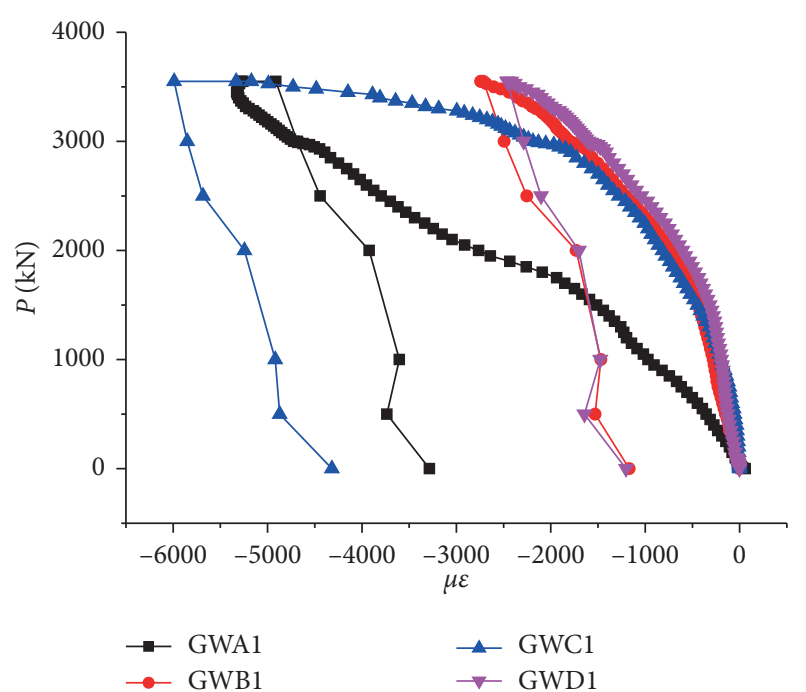

(a)

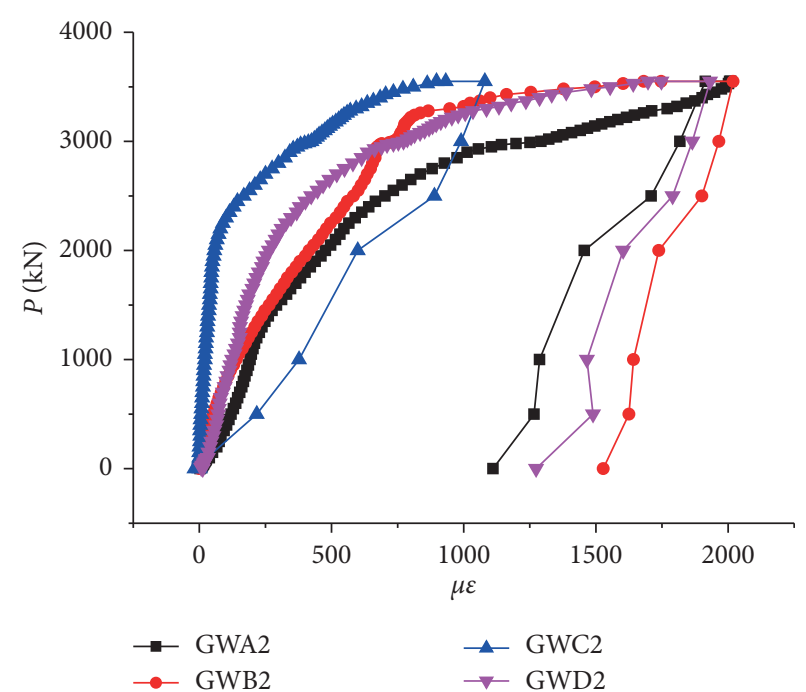

(b)

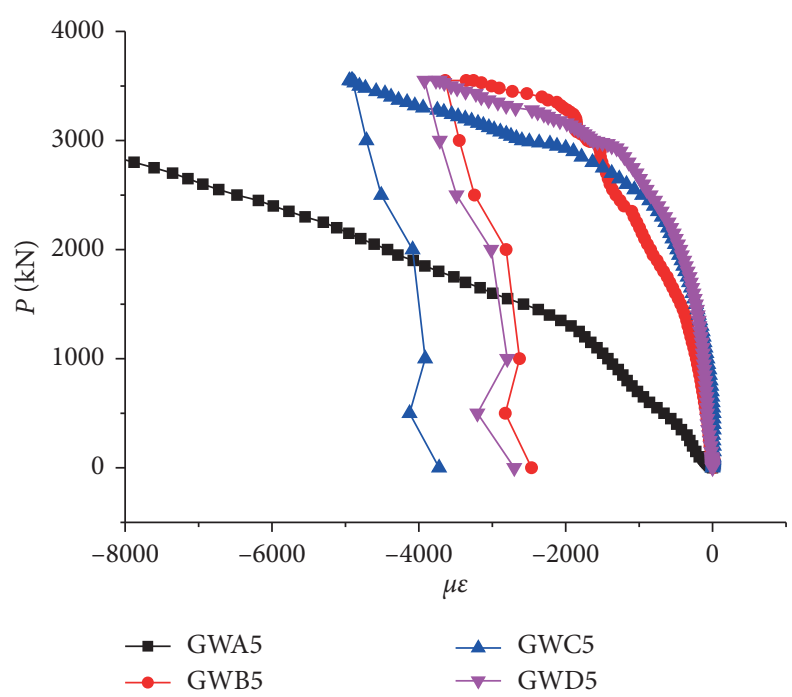

(c)

FIGURE 7: Load-strain curves of the steel tube.

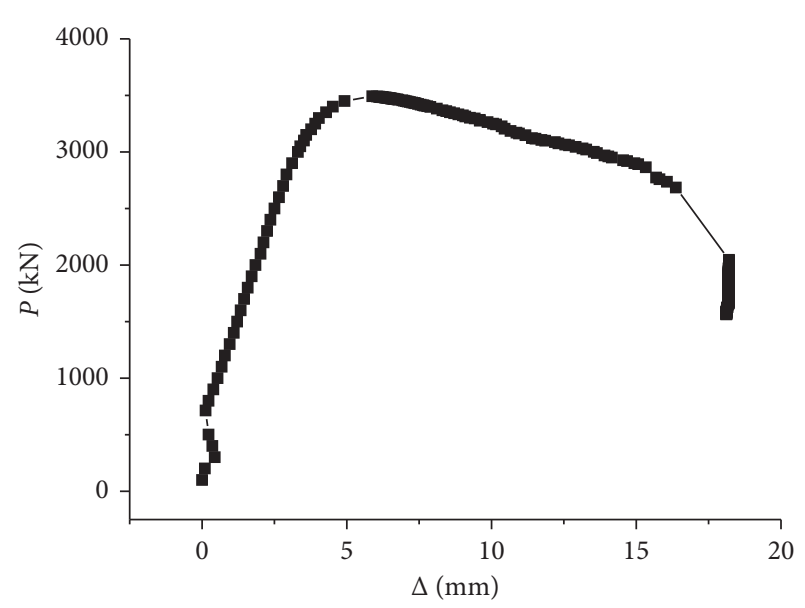

Figure 8: The load-displacement curve. the steel tube and concrete is fixed against all degrees of freedom, and the upper end is free while encountered by axial load. The nonlinear equations are solved by the incremental iterative method. Material characteristics, boundary conditions, and loading method of the finite element model are all the same as those of the test. The model is meshed freely as shown in Figure 9.

4.2. Model Verification. The comparison of experimental and modeling ultimate load-displacement curves is shown in Figure 10. A good agreement is found in general, and the discrepancies between experimental and predicted ultimate load bearing capacity are close to each other except that the ultimate displacement of the finite element model is smaller than the experimental one. In addition, the predicated cloud 


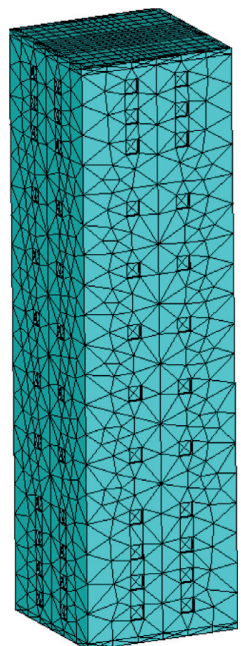

(a)

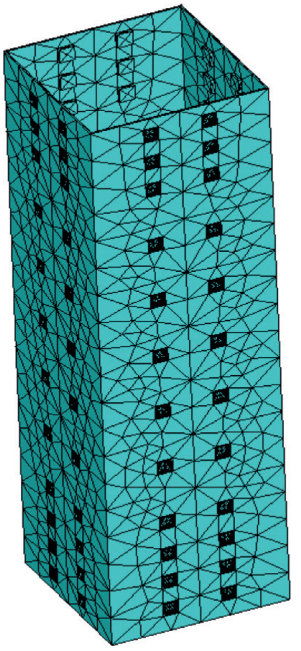

(b)

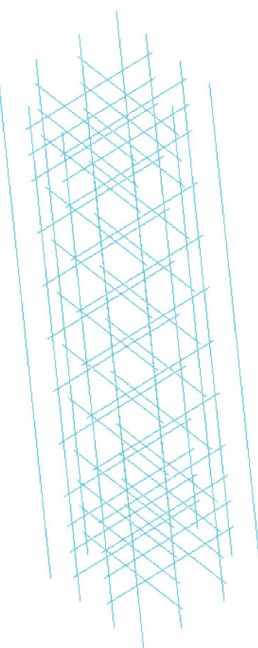

(c)

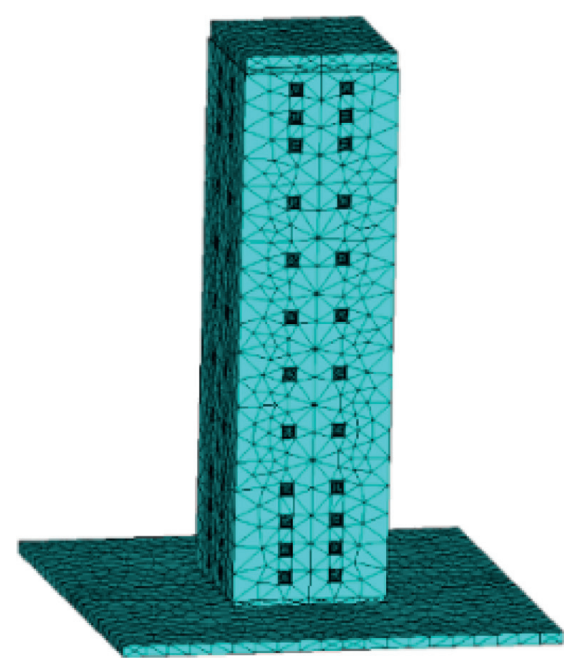

(d)

Figure 9: Models of the finite element: (a) concrete element, (b) steel tube element, (c) reinforcement element, and (d) integrated model.

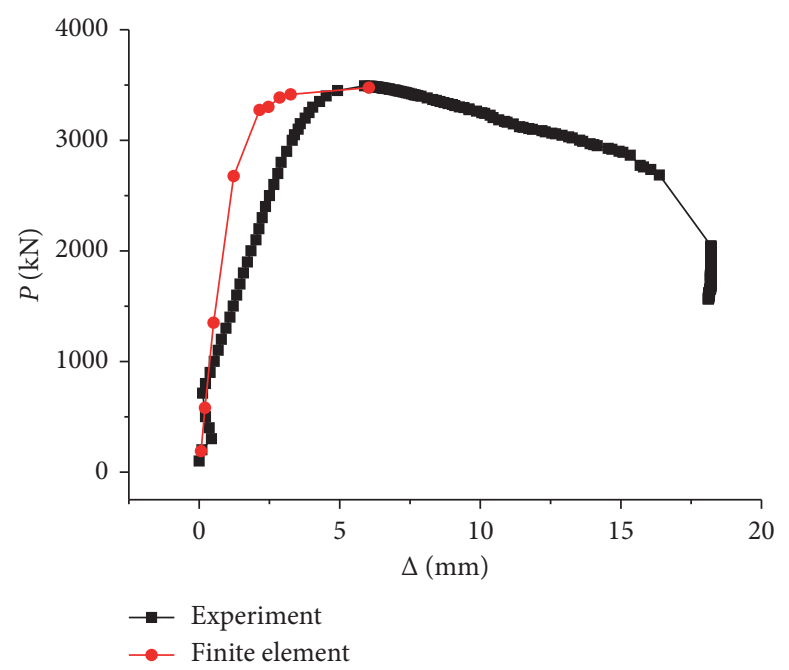

FIgURE 10: Comparison of load-displacement curves.

pictures of holistic displacement at the moment of component failure are shown in Figure 11. It can be seen that lateral bending of the column and uneven distribution of displacement at the same cross section occurred. As can be seen from these figures, local buckling of the steel tube appeared at the upper end of the steel wall which is consistent with the experimental failure modes. In all, although there is some gap between experimental and modeling results, it is feasible for parameter analysis.

\section{Parametric Studies}

The following parameters of the specimen are analyzed and discussed in order to further investigate the mechanical properties of concrete-filled square thin-walled steel tubular columns with binding bars, including spacing of binding bars, diameter of longitudinal bars, concrete strength, thickness of the steel tube wall, and section dimension of the column. During the parameter analysis, only the individual parameter is changed, and the other parameters remain unchanged as test value every time.

5.1. Effect of Spacing of Binding Bars. Comparison of loaddisplacement curves with different spacings of binding bars is shown in Figure 12. The axial bearing capacity $\left(P_{u}\right)$ and displacement $\left(\Delta_{u}\right)$ of members can be seen in Table 2. It can be known there is little effect on the load-displacement curve for different spacings of binding bars. The ultimate bearing capacity and displacement are slightly changed with the increase of the spacing.

5.2. Effect of Diameter of Longitudinal Bars. Comparison of load-displacement curves with different diameters of longitudinal bars is shown in Figure 13. The axial bearing capacity $\left(P_{u}\right)$ and displacement $\left(\Delta_{u}\right)$ of members are shown in Table 3. It can be seen that there is a little effect on the 

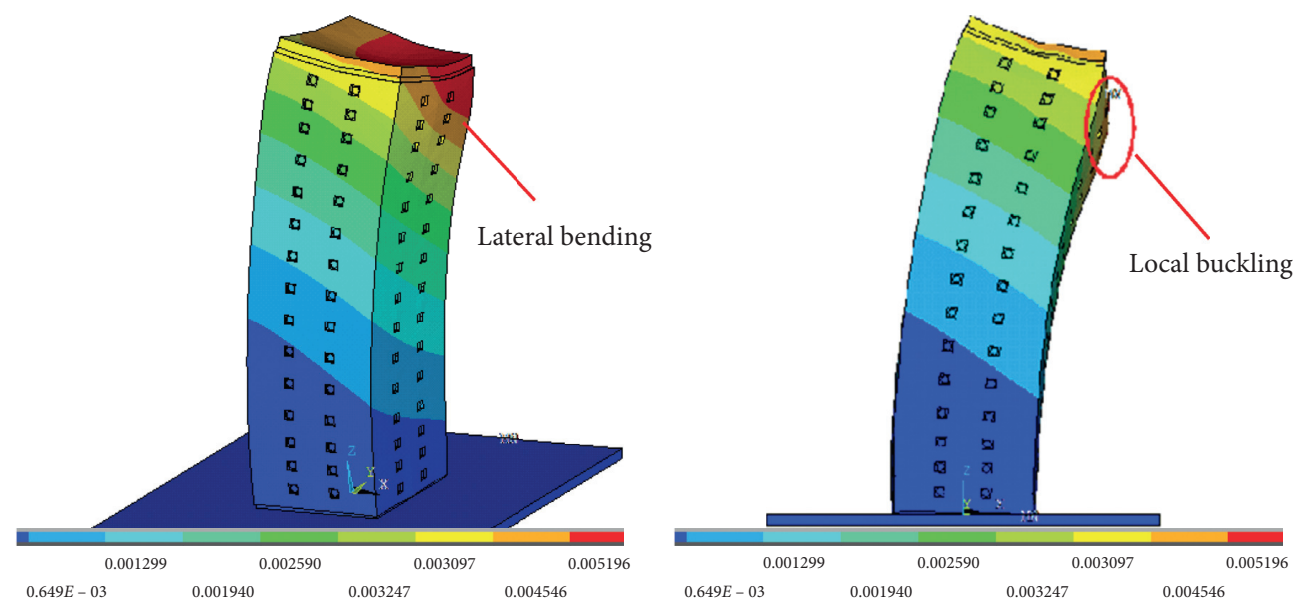

Figure 11: Cloud pictures of holistic displacement.

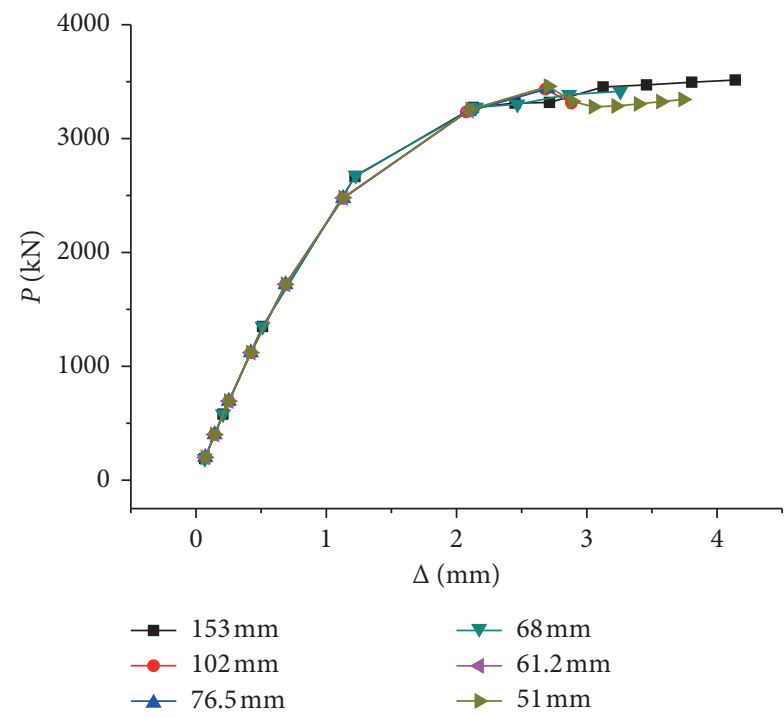

FIgURE 12: Influence of binding bar spacing on specimen performance.

TABLE 2: Influence of binding bar spacing on ultimate axial bearing capacity and displacement of the specimen.

\begin{tabular}{lcc}
\hline Spacing of binding bars $(\mathrm{mm})$ & $P_{u}(\mathrm{kN})$ & $\Delta_{u}(\mathrm{~mm})$ \\
\hline 153 & 3514.26 & 4.1403 \\
102 & 3434.64 & 2.8828 \\
76.5 & 3439.43 & 2.6999 \\
68 & 3415.27 & 3.2574 \\
61.2 & 3246.27 & 2.0963 \\
51 & 3343.11 & 3.7391 \\
\hline
\end{tabular}

elastic stiffness of the specimen. With the increase of diameter, the bearing capacity of the members increases, while the peak displacement and the ductility decrease slightly.

5.3. Effect of Concrete Strength. Comparison of loaddisplacement curves with different concrete strengths is shown in Figure 14. The axial bearing capacity $\left(P_{u}\right)$ and displacement $\left(\Delta_{u}\right)$ of members are shown in Table 4 , where

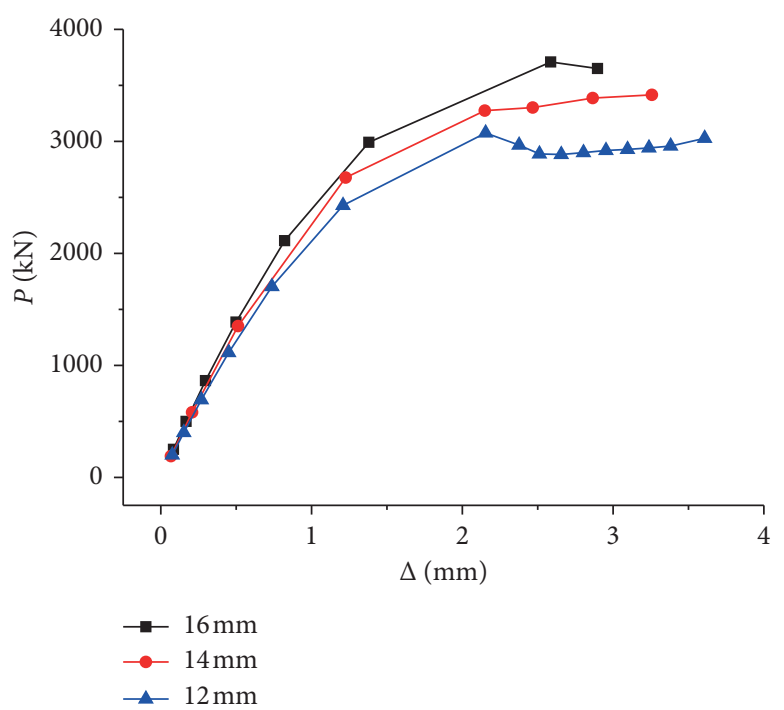

Figure 13: Influence of longitudinal bar diameter on specimen performance.

$f_{\mathrm{cu}}$ is the cube compressive strength and $f_{c}$ is the corresponding uniaxial compressive strength. It can be seen that the stiffness and bearing capacity increase with the increase of concrete strength.

5.4. Effect of Thickness of the Steel Tube Wall. Comparison of load-displacement curves with different thicknesses of the steel tube wall is shown in Figure 15. The axial bearing capacity $\left(P_{u}\right)$ and displacement $\left(\Delta_{u}\right)$ of members are shown in Table 5 . It can be seen that there is little change for the elastic stiffness and bearing capacity with the increase of the wall thickness. However, the peak displacement decreases gradually. Therefore, with the increase of thickness, there is some increase about bearing capacity and stiffness. It leads to adverse effect on the specimen performance when the wall thickness reaches a certain value. 
TABLE 3: Influence of diameter of longitudinal bars on ultimate axial bearing capacity and displacement of the specimen.

\begin{tabular}{lcc}
\hline Diameter of longitudinal bars $(\mathrm{mm})$ & $P_{u}(\mathrm{kN})$ & $\Delta_{u}(\mathrm{~mm})$ \\
\hline 16 & 3709.18 & 2.8967 \\
14 & 3415.27 & 3.2574 \\
12 & 3027.26 & 3.6075 \\
\hline
\end{tabular}

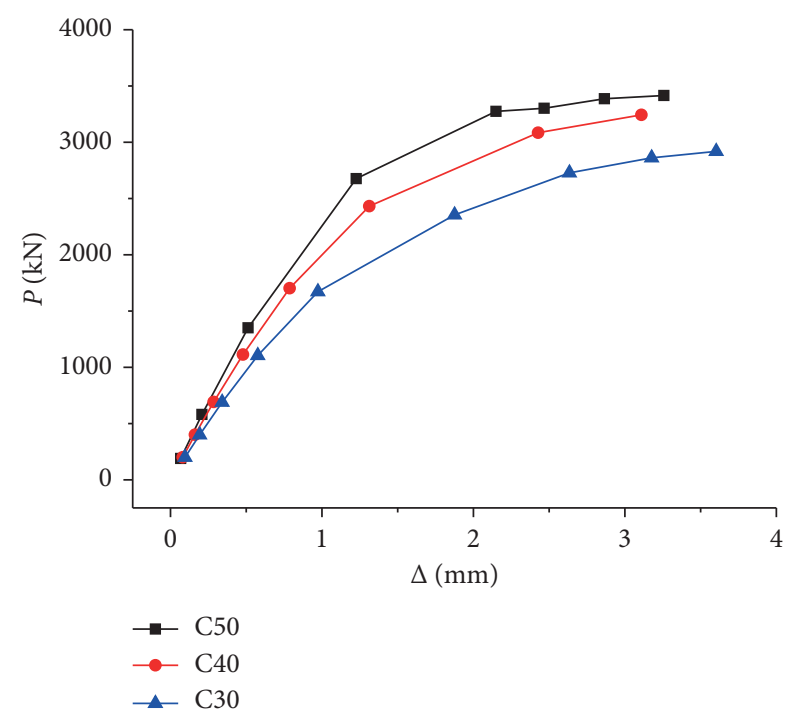

Figure 14: Influence of concrete strength on specimen performance.

TABLE 4: Influence of concrete strength on ultimate axial bearing capacity and displacement of the specimen.

\begin{tabular}{lcccc}
\hline $\begin{array}{l}\text { Concrete strength } \\
\text { grade }\end{array}$ & $f_{\text {cu }}(\mathrm{MPa})$ & $f_{c}(\mathrm{MPa})$ & $P_{u}(\mathrm{kN})$ & $\Delta_{u}(\mathrm{~mm})$ \\
\hline C50 & 50 & 23.1 & 3415.27 & 3.2573 \\
C40 & 40 & 19.1 & 3243.68 & 3.1095 \\
C30 & 30 & 14.3 & 2918.77 & 3.6033 \\
\hline
\end{tabular}

5.5. Effect of Section Dimension. Comparison of loaddisplacement curves with different section dimensions of the column is shown in Figure 16. The axial bearing capacity $\left(P_{u}\right)$ and displacement $\left(\Delta_{u}\right)$ of members are shown in Table 6 . It can be seen that the increase of cross-section size can improve the bearing capacity and stiffness. The peak displacement, bearing capacity, and ductility of the specimen with $320 \mathrm{~mm} \times 320 \mathrm{~mm}$ increase significantly.

\section{Theoretical Analysis}

The model of the square steel pipe constrained on the core concrete is assumed in Figure 17. The shaded part is an effectively confined area, and nonshadowed areas are ineffectively confined ones whose boundary lines are parabolas, where $\theta$ is a tangent slope of the boundary, $b$ is the section length, and $a_{s}$ and $b_{s}$ are the horizontal and vertical spacing of binding bars, respectively. The confinement effectiveness coefficient $k_{e}$ is given by

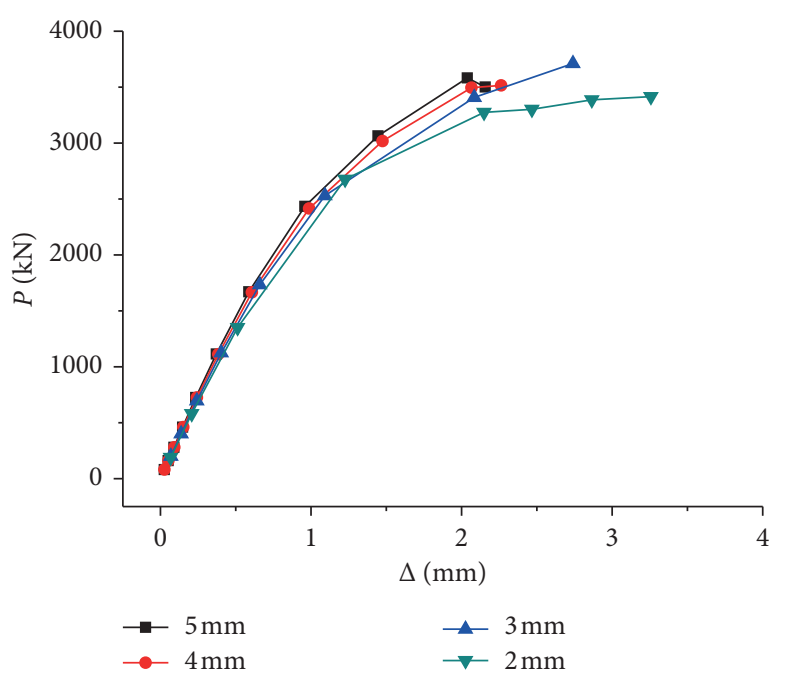

FIgURE 15: Influence of steel wall thickness on specimen performance.

TABLE 5: Influence of steel wall thickness on ultimate axial bearing capacity and displacement of the specimen.

\begin{tabular}{lcc}
\hline Thickness of the steel tube wall $(\mathrm{mm})$ & $P_{u}(\mathrm{kN})$ & $\Delta_{u}(\mathrm{~mm})$ \\
\hline 5 & 3582.14 & 2.1573 \\
4 & 3515.63 & 2.2630 \\
3 & 3710.65 & 2.8248 \\
2 & 3415.27 & 3.2573 \\
\hline
\end{tabular}

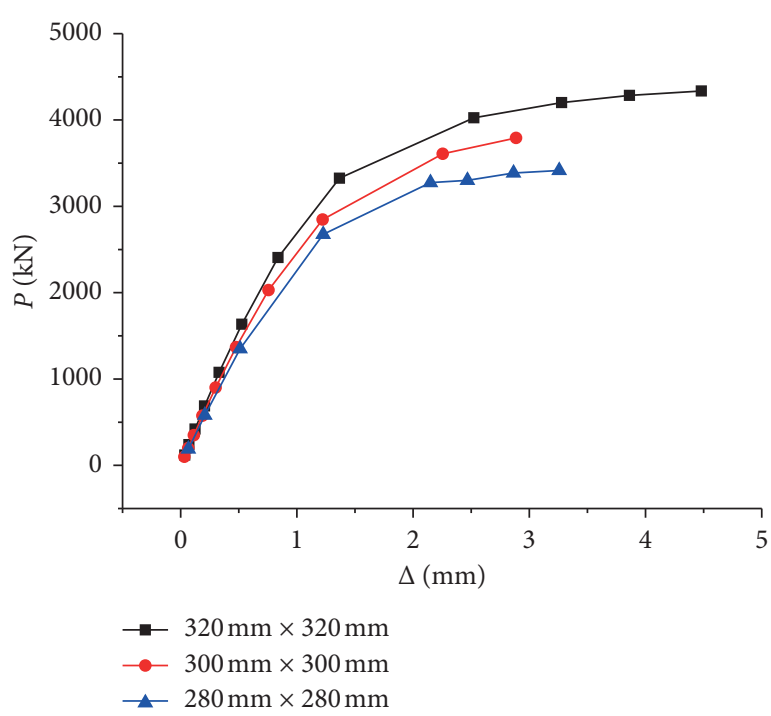

Figure 16: Influence of section dimension on specimen performance.

$$
k_{e}=\left[1-\sum_{i=1}^{n} \frac{\left(a_{s} / b\right)^{2} \tan \theta}{6}\right]\left[1-\frac{b_{s} \tan \theta}{2(b-2 t)}\right]^{2} .
$$

As shown in [8], the effective lateral confining pressure is 
TABLE 6: Influence of section dimension on ultimate axial bearing capacity and displacement of the specimen.

\begin{tabular}{llc}
\hline Section dimension of the column $(\mathrm{mm} \times \mathrm{mm})$ & $P_{u}(\mathrm{kN})$ & $\Delta_{u}(\mathrm{~mm})$ \\
\hline $320 \times 320$ & 4335.85 & 4.4799 \\
$300 \times 300$ & 3792.56 & 2.8860 \\
$280 \times 280$ & 3415.27 & 3.2573 \\
\hline
\end{tabular}

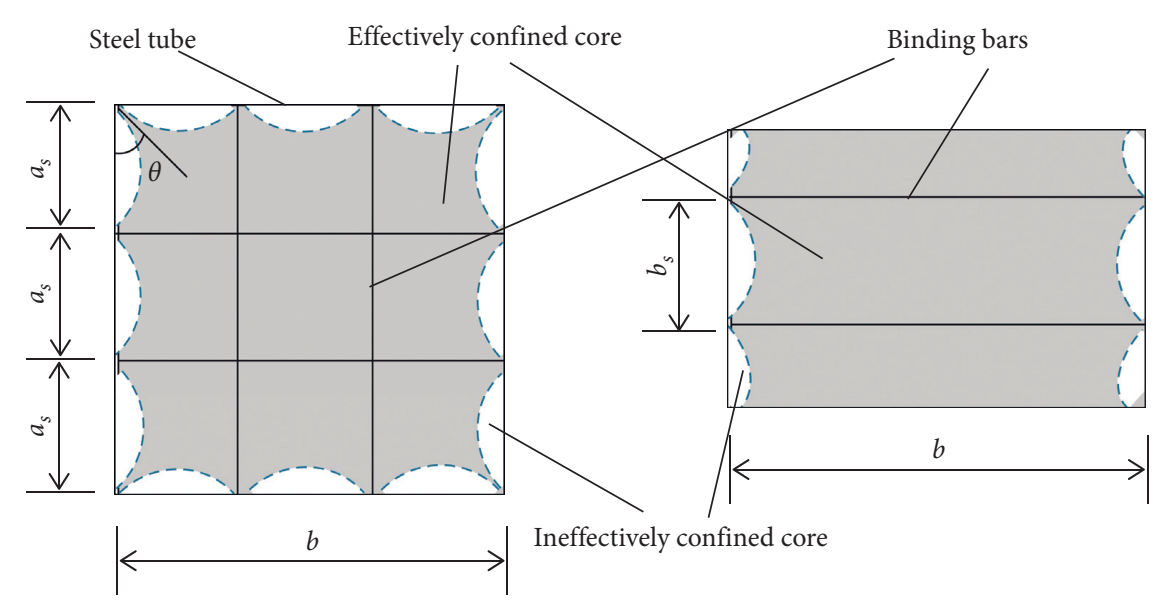

(a)

(b)

FIGURE 17: Effectively confined area of core concrete: (a) lateral section and (b) longitudinal section.

$$
\begin{aligned}
& f_{l}=k_{e} f_{l}^{\prime}, \\
& f_{l}^{\prime}=\frac{2 f_{s r}+E_{s} \varepsilon_{s}\left(A_{s}\left(b-a_{s}\right) / a_{s} b_{s} t\right)}{(b / t)-2},
\end{aligned}
$$

where $f_{l}^{\prime}$ is the lateral pressure from the transverse reinforcement, assumed to be uniformly distributed over the surface of the concrete core.

When the confined concrete core is placed in triaxial compression with equal effective lateral confining stresses $f_{l}$ from spirals or circular hoops, it can be shown that the confined compressive strength is given by Mander and Priestley in [19]:

$$
f_{\mathrm{cc}}=f_{\mathrm{co}}\left(-1.254+2.254 \sqrt{1+\frac{7.94 f_{l}}{f_{\mathrm{co}}}}-2 \frac{f_{l}}{f_{\mathrm{co}}}\right) .
$$

The meaning of each parameter in the aforementioned formulas can be seen in [8]. bars is

The bearing capacity of the STCRC column with binding

$$
N_{u}=f_{\mathrm{cc}} A_{c}+f_{y} A_{b}
$$

where $A_{c}$ and $A_{b}$ are the areas of concrete and longitudinal bars and $f_{y}$ is the yield strength of longitudinal bars, respectively.

The above theoretical equation (4) denotes the common bearing capacity of concrete and longitudinal bars, and $f_{\mathrm{cc}}$ is the compressive strength of concrete considering the confined effect from binding bars and steel tube. Axial bearing capacity of STCRC columns can be obtained with various
TABLE 7: Axial bearing capacity of the specimen.

\begin{tabular}{lccccc}
\hline$N_{e}(\mathrm{kN})$ & $N_{u 1} / N_{e}$ & $N_{u 2} / N_{e}$ & $N_{u 3} / N_{e}$ & $N_{u 4} / N_{e}$ & $N_{u 5} / N_{e}$ \\
\hline 3490 & 1.003 & 1.037 & 0.682 & 0.824 & 0.926 \\
\hline
\end{tabular}

strengths and square sections of concrete, bars, and steel tube via the equation.

The bearing capacity of the member is reached, and the binding bars and steel tube nearly yield according to the test. The stress of concrete, binding bars, and steel tube is taken as design strength as in [20]. The boundary line is assumed as approximating a quarter circle with the tangent slope $\theta=45^{\circ}$ as seen in [16].

The axial bearing capacity ratio of the specimen between test, finite element, and equation (4) is shown in Table 7, where $N_{e}, N_{u 1}$, and $N_{u 2}$ are the axial load strength from test, finite element, and equation (4), respectively. For comparison, the results of the specimens assumed as reinforced concrete (RC), CFST, and STCRC columns all without binding bars are also given here, listing out as $N_{u 3}, N_{u 4}$, and $N_{u 5}$, respectively. The formula of $N_{u 5}$ can be seen in [16]. It is easily known that the strength of the STCRC column with binding bars is the highest than that of RC, CFST, and STCRC. Although there is a little difference between the previous three results which is acceptable, the restraint effect from binding bars and steel tube on core concrete is obvious.

\section{Conclusions}

Through the experimental study, finite element parameter, and theoretical analysis on the steel tube confined reinforced 
concrete (STCRC) columns with binding bars, the following conclusions are obtained:

(1) For this type of axial compression reinforced concrete column, the core concrete is wrapped and constrained by the steel tube wall, and the steel tube wall is constrained by binding bars locally. The effect controlled and restrained by layer upon layer makes the concrete not easily to be crushed under pressure and improves bearing capacity of the column.

(2) The results of finite element and theoretical analysis agree well with those of the test. It is feasible for qualitative parameter analysis and equation (4) though they are slightly larger. The restraint effect from binding bars and steel tube on core concrete is obvious by comparing the axial bearing capacity theoretically.

(3) The parameters, including spacing of binding bars, diameter of longitudinal bars, concrete strength, thickness of the steel tube wall, and section dimension of the column, generate different influence on the mechanical properties and bearing capacity of the specimens.

\section{Data Availability}

The data used to support the findings of this study are included within the article.

\section{Conflicts of Interest}

The authors declare that they have no conflicts of interest.

\section{Acknowledgments}

This research was financially supported by the Natural Science Foundation of Chongqing (no. cstc2019jcyjmsxmX0440), the Science and Technology Research Program of Chongqing Municipal Education Commission (Grant no. KJQN201901339), the Science and Technology Project of Chongqing University of Arts and Sciences (no. 2017RJJ31), and the Major Breeding Project of Chongqing University of Arts and Sciences (no. P2018JG13).

\section{References}

[1] H. Ge and T. Usami, "Strength of concrete-filled thin-walled steel box columns: experiment," Journal of Structural Engineering, vol. 118, no. 11, pp. 3036-3054, 1992.

[2] C. S. Huang, Y.-K. Yeh, G.-Y. Liu et al., "Axial load behavior of stiffened concrete-filled steel columns," Journal of Structural Engineering, vol. 128, no. 9, pp. 1222-1230, 2002.

[3] H.-T. Hu, C.-S. Huang, M.-H. Wu, and Y.-M. Wu, "Nonlinear analysis of axially loaded concrete-filled tube columns with confinement effect," Journal of Structural Engineering, vol. 129, no. 10, pp. 1322-1329, 2003.

[4] F. X. Ding, L. Fu, Z. Yu et al., "Mechanical performances of concrete-filled steel tubular stub columns with round ends under axial loading," Thin-Walled Structures, vol. 97, pp. 22-34, 2015.
[5] M. F. Hassanein and V. I. Patel, "Round-ended rectangular concrete-filled steel tubular short columns: FE investigation under axial compression," Journal of Constructional Steel Research, vol. 140, pp. 222-236, 2018.

[6] M. X. Xia, L. Ai, and X. R. Liu, "Experimental study on the axial compressive performance of reinforced high-strength concrete filled thin-walled steel tubular column," Progressing Steel Building Structures, vol. 22, no. 1, pp. 85-91, 2020.

[7] J. Cai and Z.-Q. He, "Axial load behavior of square CFT stub column with binding bars," Journal of Constructional Steel Research, vol. 62, no. 5, pp. 472-483, 2006.

[8] J. Cai and Z. Q. He, "Constitutive relationship of square CFT with binding bars," Engineering Mechanics, vol. 23, no. 10, pp. 145-150, 2006.

[9] Y. L. Long and J. Cai, "Experimental investigation into axial compressive behavior of L-shaped concrete-filled steel tubular stub columns with binding bars," Journal of South China University of Technology, vol. 34, no. 11, pp. 87-92, 2006.

[10] J. Cai and G. Sun, "Constitutive relationship of L-section CFT with binding bars," Engineering Mechanics, vol. 25, no. 10, pp. 173-179, 2008.

[11] X. Shanbin, M. Fanqiang, Z. Peng, B. Jiuwen, W. Junjie, and Z. Kaiyue, "Influence of water re-curing on microstructure of heat-damaged cement mortar characterized by low-field NMR and MIP," Construction and Building Materials, vol. 262, Article ID 120532, 2020.

[12] Z. G. Zuo and J. Cai, "Equivalent uniaxial constitutive relationship for the encased concrete of cross-shaped steel tubular with binding bars," Engineering Mechanics, vol. 29, no. 2, pp. 177-184, 2012.

[13] X. Chen and D. Y. Zhou, "Comparison among axial behaviors of rectangular CFT stub column by adopting five material models of concrete," Journal of Building Structures, vol. 30, no. 3, pp. 120-125, 2009.

[14] Z. G. Ren, C. Liu, D. D. Wang et al., "Axial compression mechanism of round-ended concrete-filled steel tubular stub short columns with binding bars," Journal of Architecture and Civil Engineering, vol. 36, no. 5, pp. 39-51, 2019.

[15] S. M. Zhang, J. P. Liu, L. Ma et al., "Axial compression test and analysis of circular tube confined HSC stub columns," China Civil Engineering Journal, vol. 40, no. 3, pp. 24-31, 2007.

[16] X. H. Zhou, D. Gan, J. P. Liu et al., "Experiment and analysis on square tubed reinforced concrete stub columns under axial compression," Journal of Building Structures, vol. 32, no. 2, pp. 68-74, 2011.

[17] X. H. Zhou, B. Yan, and J. P. Liu, "Axial load behavior of circular tubed reinforced concrete columns with different length-to-diameter ratios," Journal of Building Structures, vol. 39, no. 12, pp. 11-21, 2018.

[18] C. Y. Gao, M. Y. Liu, Y. X. Duan et al., "Experimental study on mechanical properties of the tube confined reinforced concrete compression members," Journal of Xi'an University of Architectural Science and Technology (Natural Science Edition), vol. 51, no. 6, pp. 833-838, 2019.

[19] J. B. Mander and M. J. N. Priestley, "Theoretical stress-strain model for confined concrete," Journal of Structural Engineering, ASCE, vol. 114, no. 8, pp. 1807-1826, 1988.

[20] GB 50010-2010, Code for Design Concrete Structures, China Architecture \& Building Press, Beijing, China, 2015. 